\title{
Uzaktan Eğitimde Etkili İletişim ve İletişimsel Engeller: Sözlü ve Sözsüz İletişim
}

\author{
Yunus Emre Sarı (D), İstanbul
}

\section{https://doi.org/10.37583/diyalog.1030779}

$\ddot{\partial} z$

İletişimin yeni medya aracılığı ile sesli ve görüntülü olarak yapılabiliyor olması eğitimde birçok kolaylı̆̆ı beraberinde getirmektedir. Bu yeni iletişim ve eğitim şeklinin günden güne insanların hayatına daha çok girmesiyle uzaktan eğitimde nitelik kavramı ve didaktik uygulamaları tartışılmaktadır. COVID-19 pandemisinin ortaya çıkmasıyla eğitim ve öğretimin devamlılığını sağlamak için 2020 yılında birçok ülkede uzaktan eğitime geçilmiştir. Uzaktan eğitimin bu büyüklükteki bir kitleye daha önce uygulanmamış olması bazı olumsuzlukları da beraberinde getirmiştir. Yüz yüze eğitimden kısa bir süre içinde uzaktan eğitime geçiş yapılması gerek öğreticileri gerekse öğrenenleri birtakım yeniliklerle karşı karşıya bırakmıştır. Bu yeniliklerle birlikte çevrimiçi sesli ve görüntülü iletişim araçlarının eğitimde daha aktif olarak kullanılması söz konusu olmuştur. Birtakım sebeplerle eş zamanlı uzaktan eğitimde, iletişim araçlarının kapalı şekilde olmalarından faydalanılmıştır. Bu durum etkili bir iletişim ortamının gerçekleşmesini olumsuz yönde etkileyebilir.

Mevcut çalışmada etkili bir eşzamanlı uzaktan eğitimde iletişimin önemi ve iletişimsel süreçleri etkileyen faktörler, ilgili alanyazın doğrultusunda ele alınmıştır. Çalışmada iletişim kavramı ve modelleri, sözlü ve sözsüz iletişim, eğitimde iletişim, yabancı dil eğitiminde iletişim ve uzaktan eğitimde iletişim gibi kavramlar üzerinde durularak, sesli ve görüntülü iletişim türlerinin uzaktan eğitim için iletişim anlamında taşıyacakları önem ve gereklilik tartı̧ılmıştır.

Anahtar Sözcükler: Etkili İletişim, Uzaktan Eğitim, İletişim Modelleri, İletişimsel Engeller, Sözlü ve Sözsüz Iletiş̧im.

\section{Abstract \\ Effective Communication and Communication Barriers in Distance Education: Verbal and Nonverbal Communication}

Being able to communicate with audio and video through new media brings many practical benefits to education. As this new form of communication and education is entering people's lives more and more every day, the concept of qualification and didactic applications in distance education are discussed. With the emergence of the COVID-19 pandemic, distance education was introduced in many countries in 2020 to ensure the continuity of education and teaching. The fact that distance education has not yet been applied to such a large audience and at different levels has brought some negative effects. The transition from faceto-face to distance learning in a short period of time has forced both teachers and learners to learn and practice a new set of normalities. 
It is known that cameras are usually turned off in distance learning procedures. There are advantages and disadvantages associated with this situation. In this study, the importance of communication in effective training is discussed based on the relevant literature and conclusions are drawn regarding effective training in distance education. In this study, the importance of communication in effective teaching is discussed based on the relevant literature and conclusions are drawn about effective teaching in distance education. In the study, concepts such as models of communication, verbal and non-verbal communication, communication in education, communication in foreign language education and communication in distance education are discussed, and why the cameras should be open in simultaneous distance education.

Keywords: Effective Communication, Distance Education, Communication Models, Effective Learning, Verbal and Nonverbal Communication. 


\section{EXTENDED ABSTRACT}

In the present study, firstly, the concept of communication will be discussed within the framework of classical models. Then, the concept of communication in education and foreign language education will be presented. On this basis, the importance of verbal and nonverbal communication in simultaneous distance education will be analyzed depending on the relevant literature. From this point of view, the importance of having cameras on/ off for effective communication will be shown on the basis of the relevant literature. Faced with the COVID-19 pandemic, some forms of distance education in Turkey are taking advantage of technologies that use videoconferencing software to enable simultaneous classroom meetings over the internet. In this study, distance education, in which a teacher and learners are simultaneously in an online course environment, is meant under the name of distance education. Considering this, it is important to have certain qualifications that distinguish simultaneous distance learning from video lectures. The concept of simultaneous distance education should be different from the students watching video lessons alone or collectively, and this is only possible with a quality communication between teacherstudent and student-student.

In daily life, the concept of communication has gained different meanings specific to each field, as well as in different fields. In this context, it is almost impossible to make a definition that is accepted by everyone, but when it comes to communication, scientists stated that verbal and nonverbal communication are in question. Despite the development of technology, if there is still a lack of communication when using modern communication tools, it is because nonverbal communication cannot be used effectively in the tools in use. A quality learning environment in distance education can be achieved if both students and instructors have multimedia skills and sufficient distance education equipment. At the same time, the most basic distance learning equipment such as an age-appropriate computer, webcam, headset microphone, ergonomic desk and chair, and a good Internet connection are also required.

It is thought that many educators who are accustomed to face-to-face education have applied some sanctions in order to feel themselves in a difficult situation in distance education and not to lose control of the classroom. Among the most important of these is to turn off the video communication and to continue the education with only the voice of the teacher and the teaching material reflected on the screen. In addition, it is known that the cameras are turned off because the students do not want to give up their sense of comfort or because they do not have a camera. In addition, it is known that the cameras are turned off in order to prevent the internet infrastructure and programs such as Zoom used for distance education from being forced. In accordance with the decision taken by the Ministry of National Education, it was requested that the cameras and microphones of the students should be turned off in general, but should be turned on when necessary. There is no provision in any article regarding the obligation of teachers whether to turn on the cameras or not. However, communication is not just an auditory phenomenon consisting of words or sounds. Communication is considered as a whole, which is performed non-verbally in addition to verbal communication. Under this aspect, it may be possible to limit communication to verbal communication, which reduces the quality of communication and, consequently, the quality and efficiency of teaching. If this situation is considered for distance education, it is seen that the communication process should be more than a voice exchange. An effective distance education is therefore a process in which all participants have individual responsibilities, they should be ready both physically and psychologically as if they were in face-to-face education, and communication is made in audio and visual form. 
Instructors and learners should not see online classes as different from face-to-face education and should open communication channels at both camera and microphone level. Again, a similar situation is the reservations of the students about the visual data and their inability to prevent it. This situation shows that in simultaneous online education, it is necessary to be temporally and spatially dependent and responsible during the lesson. At this point, educational institutions have duties and responsibilities in conveying the operation of simultaneous distance education and the issues that need attention. 


\section{Giriş}

Eğitim ve öğretimde internet teknolojilerinin kullanımı son y1llarda giderek ivme kazanmıştır. Böyle bir eğitim modelinde öğretmen ve öğrencilerin görev ve sorumlulukları değişirken, diğer yandan bu ortamlardaki eğitimin nitelik sorunsalı tartışılmaya başlanmıştır. Bu bakış açısıyla uzaktan eğitimde hangi önemli unsurların etkili olduğunun bilinmesi önem arz eder.

Alanyazında ${ }^{1}$ farklı tanımlarla karşımıza çıkan uzaktan eğitim kavramı, eğitim ve öğretim amacı güden başlı başına bir organize yapı olabileceği gibi, aynı zamanda, eş zamanlı ya da ayrı zamanlı olarak, teknolojik bir aygıt ile yapılabilen bir öğretim faaliyeti de olabilmektedir. Günümüzde internet teknolojileri sayesinde hayatı kolaylaştıran bir kavram haline gelen uzaktan eğitim, artık geleneksel eğitim için de alternatif olabilecek duruma gelmiştir.

Teknolojinin eğitimle bütünleşmesi sürecinde farklı uygulamalar ve kullanımlarla karşılaşılmaktadır. İlgili alanyazında uzaktan öğrenme, internet tabanlı öğrenme, eşzamanlı - eşzamanlı olmayan uzaktan eğitim, bilgisayar destekli öğrenme gibi isimlerle karşılaşılmaktadır (Bay vd. 2021: 187). Bu çalışmada uzaktan eğitim adı altında bir öğreticinin ve öğrenenlerin eş zamanlı olarak çevrimiçi ders ortamında oldukları uzaktan eğitim kastedilmektedir. Bu bakış açısıyla eş zamanlı uzaktan eğitimi video derslerden ayıracak belli niteliklerinin olması şarttır. Eş zamanlı uzaktan eğitim kavramını tartışırken, öğrencilerin tek başlarına ya da topluca video ders izlemelerinden farkının olması gerekir, bu da öğretmen-öğrenci ve öğrenci-öğrenci arasında kaliteli bir iletişimin olmasiyla mümkündür.

Kaysi / Aydemir (2017: 779) öğrenenlerin uzaktan eğitimi tercih etme nedenlerinin göz önünde bulundurulmasına vurgu yapar ve özellikle zamansal ve mekânsal bağımsızlık, öğrenenler arası etkileşimin artması, öğretim elemanlarının ulaşılır olması gibi unsurların önem taşıdığını belirtir. Kaysi / Aydemir (2017: 780) uzaktan eğitimde öğretim elemanının rolünün kaliteli iletişimi kolaylaştırmak, beslemek ve teşvik etmek olduğunu vurgulamışlardır.

Uzaktan eğitimde özellikle fiziksel uzaklığa bağlı ortaya çıkabilecek iletişim sorunlarının azaltılması önemlidir. Moore bu durumu 1970'li yıllarda ortaya attığ Bağımsız Öğrenme Kuramı'nda şu şekilde açıklar: Uzaktan eğitimde öğretmen ve öğrenciler arasındaki mesafe katılımcılar arasında yanlış anlaşılmaya neden olabilen psikolojik boşluğa sebep olabilir. Bu boşluğa Transaksiyonel Uzaklık denir. Yani bu, çevrimiçi ortamda öğretici ya da öğrenen tarafından hissedilen duygusal uzaklık (ayrılık) hissidir (Horzum 2011: 1573). Sesli ve görüntülü olan eşzamanlı bilgi aktarımı yoluyla bu uzaklığın ortaya çıkardığı engeller giderilebilir. Moore'un bu kavramı ortaya attığ zamanki teknolojik imkânlarla günümüz arasında fark vardır. Eş zamanlı veri aktarımına imkân sağlayan programlar gerek kamera gerekse mikrofon sayesinde bu uzakl1k hissinin azaltılmasını sağlamaktadırlar.

\footnotetext{
${ }^{1}$ Alanyazın terimine birleşik ya da ayrı olarak rastlanmaktadır. Bu çalışmada Mehmet Akif Ocak'ın Alanyazın İncelemesi (2021) adlı kitabı örnek alınarak birleşik yazılmıştır.
} 
Ammenwerth / Hackl'e (2016: 48)'e göre, dijital öğrenme ortamlarında sosyal etkileşim süreçlerinin desteklenmesi, katılımcıların mekânsal olarak ayrı olmaları nedeniyle oldukça zor bir süreçtir. Ancak 2020 yılında ortaya çıkan COVID-19 pandemisi sebebiyle ilk, orta ve yükseköğrenim kurumlarında zorunlu olarak uzaktan eğitim sürecine geçilmiştir. Uzaktan eğitim için kullanılmakta olan dijital platformlar eğitim ve öğretim hayatında yeni bir çağın başlangıcı olarak kabul edilse de (Sucu 2020: 558) beraberinde yeni birtakım sorunsalları da getirmiştir.

Pandemi sürecinde eğitimin ve öğretimin sürdürülebilmesi için Yükseköğretim Kurulu (YÖK) önderliğinde mevzuat, altyapı, insan kaynakları, içerik ve uygulama alanlarında düzenlemelere gidilmiştir. 2019/ 2020 Eğitim-Öğretim Yılı, Bahar Yarıyılında 123 üniversitede UZEM (Uzaktan Eğitim Merkezi) tespit edilmiş ve merkezlerin lider bir rol üstlenerek uzaktan eğitim şeklinde bu dönemin sürdürülmesi istenmiştir. Uygulamalı lisans derslerin teorik kısımlarının uzaktan eğitim ile tamamlanması, uygulamalı kısımlarının ise uygun zamanda sıkıştırılmış olarak gerçekleştirilmesi tavsiyesinde bulunulmuştur. Sosyal bilimler alanlarında teorik derslerin ağırlıklı olması uzaktan eğitime adaptasyonu kolaylaştırarak bu dönemin daha rahat geçirilmesini sağlamıştır (Genç vd. 2020: 136). Bu durum eğitim ve öğretim alanında çalışan araştırmacıları "uzaktan eğitimde nitelikli bir öğretim nasıl yapılmalı?" sorusunun yanıtını aramaya itmiştir.

Yüz yüze eğitime alışkın birçok eğitimcinin uzaktan eğitimde kendilerini zor durumda hissettikleri ve bununla beraber sınıfın kontrolünü kaybetmemek adına bir takım yaptırımlar uygulamış oldukları düşünülmektedir. Bunlardan en önemlileri arasında görüntülü iletişimin öğreten tarafından kapatılarak eğitimin sadece öğretmenin sesi ve ekrana yansıtılan öğretim materyaliyle sürdürülmesidir. Ayrıca öğrencilerin konfor hislerinden vaz geçmek istemedikleri için onların da kameralarının kapalı olduğu bilinmektedir. Bununla beraber internet alt yapısının ve uzaktan eğitim için kullanılan Zoom gibi programların aşırı yüklenme nedeniyle zorlanmasını engellemek amacıyla da kameraların kapatıldığı ileri sürülmektedir. Bu noktada, Millî Eğitim Bakanlığınca Eğitim Bilişim A ğı (EBA) uygulaması ile EBA TV programlarını geliştirerek, uzaktan eğitim programlarının altyapılarını geliştirmeye yönelik yoğun çalışmalar başlatılmıştır. Aynı zamanda faklı uygulamaların kullanımına da izin veren MEB, öğretmenlerin ve öğrencilerin uzaktan eğitim sürecinde uymaları gereken Etik ve Disiplin Kurallarına da yeni maddeler eklemişlerdir. Öğrencilerin kişisel verilerin korunmasına yönelik yapılan bu düzenlemelerde, canlı derslerde öğrencilerin gerekli olmadıkça kameralarının kapalı olması ve yalnızca zorunlu hallerde açılması, bu yetkinin de öğretmende olduğu belirtilmiştir. Dersin işlenişi sırasında öğretmenlerin mikrofonları açık, öğrencilerin mikrofonları ise konuşmadıkları sürece, sesin dijital ortamda öğrenciler arasında yankı oluşturabilmesi sebebiyle, kapalı olması gerektiği vurgulanmıştır (MEB 2020). Öğretmen kameralarının açık tutulması ile ilgili bir zorunluluktan herhangi bir maddede bahsedilmemektedir. Oysa iletişim, yalnızca kelimelerden ya da seslerden oluşan işitsel bir olgu değildir. İletişim sözlü iletişime ek olarak, sözsüz olarak da gerçekleştirilen bir bütün olarak ele alınmaktadır. Bu durumda iletişimin sadece sözlü iletişimle sınırlanması, 
iletişimin kalitesinin ve dolayısıyla da dersin niteliğinin ve verimliliğinin düşmesi anlamina gelebilir.

Mevcut çalışmada ilk olarak iletişim kavramı klasik modeller çerçevesinde ele alınacaktır. Daha sonra eğitimde ve yabancı dil eğitiminde iletişim kavramına değinilecektir. Bu temelde eş zamanlı uzaktan eğitimde sözlü ve sözsüz iletişimin önemi ilgili alanyazına bağlı olarak tartışılacaktır.

\section{İletişim Kavramı}

Sosyal bir varlık olan insan, çevresiyle sürekli iletişim kurma ihtiyacı duymaktadır. İletişim kavramı günlük hayatta, sadece konuşma eylemi olarak düşünülmektedir. Oysa iletişimin tanımlarına bakıldığında yalnızca konuşma ile sınırlı olmadığı aynı zamanda birçok etkeni içerisinde barındırdığı görülmektedir. Erdoğan'a (2005: 42) göre "iletişim; belli yer ve zamanda, belli şartlarda, belli tarihi ve geçmişi olan insan etkinliğinin yapılmasının zorunlu koşuludur". Bu ifadesiyle Erdoğan (a.g.e), kültürün içerisinde bulunduğu toplumdan ayrı olarak düşünülemeyeceğini vurgulamaktadır. Zıllığglu (2007: 22) ise iletişimi, "anlamları itibarıyla uzlaşılmış simgeler yoluyla değişik zaman ve mekân boyutlarında gerçekleşen bilgi, düşünce ve duyguların aktarılması ve alışverişidir" şeklinde yorumlayarak yalnızca bilgi aktarımına değil aynı zamanda da duyuların aktarımına dikkat çekmiştir.

Günlük hayatta iletişim kavramı farklı alanlarda yer aldığı gibi, her alana özgü farklı anlamlar da kazanmıştır. Bu bağlamda herkes tarafından kabul gören bir tanım yapmak neredeyse imkânsızdır ancak iletişim denildiğinde akla sözlü ile sözsüz iletişimin gelmesi gerektiği bilim insanlarınca ortaya konulmuştur (bkz. Erkuş / Günlü 2009: 10).

Sözlü iletişim sesin iletildiği ve duyma eyleminin gerçekleştiği eylemleri kapsamaktadır. Bu noktada, konuşma dili olarak da adlandırılan sözlü iletişim düşüncelerimizi, niyetimizi ve eylemlerimizi sözcüklerle dile getirerek karşımızda bulunan kişiye kendimizi ifade etmemiz şeklinde açıklanabilir (Erdönmez 2019: 84). Sözsüz iletişim ise, söz ve sözcüklere gereksinim duyulmadan; jest, mimik, göz kontağ 1 ve beden dilinin kullanılmasıyla gerçekleştirilen bir iletişim türüdür (Berk 2014: 576).

Beden, ses ve sözcüklerin iletişimi hangi açılardan etkilediğini belirlemek için çalışmalar yürüten araştırıcılara göre, bedenin $\% 55$, sesin (ses tonu ile sesin yükselip alçalması) $\% 38$, sözcüklerinse $\% 7$ oranında etkili olduğu ortaya koyulmuştur (Üstünsel 2011: 40). Berk'e göre iletişim daha konuşmaya başlanmadan önce gerçekleşir. Teknolojinin bu denli gelişmesine rağmen, modern iletişim araçları kullanılırken hala bir 'iletişim eksikliğinden' söz ediliyorsa, bunun sebebi sözsüz iletişimin kullanılmakta olan araçlarda etkin bir şekilde kullanılamamasıdır (2014: 576). 


\section{İletişimde Klasik Modeller ve Kamera Sorunsalı}

İletişim kavramını açıklayan alanyazından hareketle, insanlar arasında hem sözlü hem sözsüz iletişimin birbirlerinden bağımsız gerçekleşmediğini söylemek mümkündür. Çünkü sözsüz iletişimde duygular belirtilirken, düşünceler ise sözlü iletişimle iletilir. $\mathrm{Bu}$ birbiriyle ilişkili gerçekleşen iletişimde, sürecin ve iletişimde yer alan öğelerin ayrılabilirliğini, işleyiş düzenleri iletişim kuramcıları tarafınca açıklanmaya çalışılmıştır (Zillığlu 2007: 92).

1940'l1 y1llarda ortaya atılan, matematiksel bir kuram niteliğinde olan Shannon ve Weaver modelinde, iletişim basit ve doğrusal bir süreçtir (İplikçi 2015: 18), bu mekanik süreç içinde iletişimin pragmatik boyutu kendine yer bulamamıştır. Bu modelde kaynağın gönderdiği kodlanmış ileti, kanal aracılığı ile alıcıya ulaşarak çözümlenir ve orada bir anlama sebep olur. Bu noktadan bakıldığında iletişimin öğeleri; kaynak, mesaj, kanal, alıcı ile dönüt olarak ayrılmaktadır (Kızıloluk 2001: 153).

Kaynak iletişim sürecinde, mesajı gönderen yani iletişim sürecini başlatan öğedir. Algılama, seçme düşünme veya yorumlama ile oluşturulan iletileri, simgeler ile kişiye ya da kişilere iletendir. Mesaj, sözlü ya da sözsüz olarak gerçekleşebilen, kişinin karşı tarafa iletmek istediği fikir, düşünce ya da duygudur. Kanal, mesajın iletişim sürecinde kaynaktan, iletişim sağlanan kişiye ulaşmasını sağlayan araçtır. Alıcı, kaynak tarafından gönderilen mesajları anlayıp, yorumlayan ve bu bağlamda mesajlara hem sözlü hem de sözsüz olarak karşılık veren kişi ya da kişilerdir. Dönüt ise alıcının iletilen mesajına verdiği tepkidir. Bu durumda mesajı nasıl yorumladığını gösterir (Kızıloluk 2001: 153; Bayraktar 2015: 266). İletişim sürecinin temel öğelerine bakıldığında, iletişimin kaynak tarafından başlatıldığı ve bunun için öncellikle iletmek istediği mesajı zihninde bir fikir olarak tasarlaması gerektiği söylenebilir. Bu bağlamda iletişim, karşı tarafa iletilmek istenen fikrin gerek beden diliyle gerekse sözel olarak mesaja dönüştüğü bir süreçtir ki, kanalın nasıl kullanılacağı (ses tonu, söyleyiş tarzı, dokunma vs.) kaynak tarafından belirlenir. Belirlenen kanalın ardından iletilen mesaj alıcıya ulaşır ve alıcı gönderilen mesaja karşılık yanıt verir, kısacası geri bildirimde bulunur (Bayraktar 2015: 267).

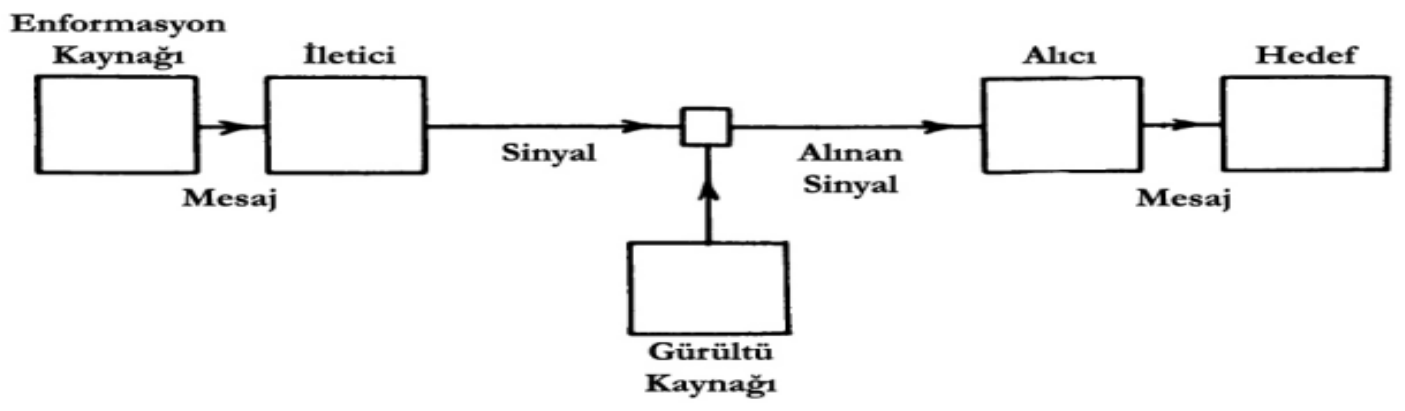

Şekil 1: Shannon Weaver İletişim Modeli (Akt. Çalışkan 2009: 29)

Klasik iletişim modelleri arasında adından çok bahsedilen ve 4 kulak ya da iletişim dörtgeni olarak adlandırılan F. Schulz von Thun'a ait modeldir. Güçlü yönlerinden birisi pratikliğidir. Örneğin, kişinin kendi iletişim davranışını eleştirel olarak gözden geçirmesi 
için çok uygundur. Bununla birlikte, bu model deneye dayalı olarak kanıtlanmamıştır ve daha çok buluşsal bir değere sahiptir. İnsan iletişimine dört farklı açıdan bakmayı önerir. Bunlara gönderen kişi tarafında olan "dört gaga" da denir, alıcı tarafındakiler ise "dört kulak" olarak adlandırılır, yani bir mesajın dört yönü bulunmaktadır. Bunlar: içerik (yalın bilgi), kendini ifşa, ilişki ve çağrıdır (Röhner / Schütz 2020: 31). Her mesajın dört yönü olmasına rağmen, mesajı alan kişi her yöne aynı önemi vermeyip, hangi kulakla dinliyorsa ona göre tepki verebilir. Bu kulak mesajı gönderen kişinin vurguladığ aynı yönde değilse, kişiler arasında iletişim kopukluğu yaşanması kaçınılmazdır (Demir: 2020).

Alanyazında adından sıkça bahsedilen diğer bir model Watzlawick Modelidir (1969). Bu model durağan alıcı-verici modeli olarak tanımlanan Shannon Weaver Modeline kıyasla dinamik ve etkileşimlidir. Diğer bir değişle, bu modelde iletişim daireseldir ve sadece B kişisinin A kişisinin sözlerine verdiği tepkiler değil aynı zamanda B'nin tepkisine A'nın verdiği cevap da önemlidir (Röhner / Schütz 2020: 38). Bu dairesel iletişimde insanların niyetlerinin önemli olduğu dolayısıyla iletişimin sadece olgusal bilgi alışverişi ile ilgili olmadığı belirtilmektedir. Buna örnek olarak, iş başvurusunda bulunan kişilerin ön görüşme sırasında güçlü yönlerini vurgulama ve zayıf yönlerini gizleme eğiliminde olmaları gösterilebilir (Röhner / Schütz 2020: 39). Paul Watzlawick'in iletişim modeli beş önermeye (aksiyom) sahiptir. Bunlar şu şekildedir: 1. İletişimsizlik mümkün değildir. 2. Her iletişimin bir içeriği ve bir ilişki yönü vardır. 3. İletişim süreçleri farklı şekilde yapılandırılmıştır. 4. İnsan iletişimi dijital ve analog modalitelerden yararlanır. Bir iletişimin içerik yönü çoğunlukla dijital olarak, ilişki yönü ise çoğunlukla analog olarak iletilir. Karşılıklı konuşmada sesli iletişime (dijital modalite) ek olarak, beden dili, konuşma tarzı ve bağlam (analog modalite) her zaman dikkate alınmalıdır. 5. Kişiler arası iletişim süreçleri, ya eş değer ya da birbirini tamamlayıcı olarak ortaya çıkar ki bu durum kişilerin arasındaki ilişkinin özdeşlik durumu ya da farklılık durumuna göre değişir (Röhner / Schütz 2020: 39-45).

Özellikle 4. ve 5. önermelerden de anlaşıldığ gibi, iletişim sadece seslerden ibaret olmayıp birçok boyuta sahip dinamik bir süreçtir. Uzaktan eğitimin mekânsal uzaklığının verdiği özgüvenin bir yönüyle 5. önermedeki statü farklılıklarının önüne geçtiği söylenebilir. Fakat bu durumda kameraların kapalı olması ayrı bir sorunsalı da doğuracaktır çünkü sadece sesli veri aktarımı 4. önermedeki analog modalitenin kaybolmasına dolayısıyla iletişimin bütünlüğünün bozulmasına sebep olacaktır.

Castelli / Sarvary (2020: 3570-3572) kameraların uzaktan eğitimde neden öğrenciler tarafından açılmak istenmediğini araştırmak için öğrencilerle yaptıkları nicel tarama çalışmasında önemli verilere ulaşmışlardır. Elde edilen sonuçlardan bazıları şu şekildedir: 1. kişisel görünümle ilgili bildirimler, 2. ortamdaki diğer insanları ve fiziksel konumu arka planda göstermek istememek, 3. zayıf bir internet bağlantısına sahip olmak, 4. sınıf arkadaşlarının veya eğitmenlerinin dikkatini dağıtma endişeleri, 5. kameralarının çalışmıyor olması. Çalışmadan çıkan sonuçlar göstermektedir ki, öğrencilerin kameraları kapatma sebepleri aslında bazı çekince ve ön yargılardan oluşmaktadır. Bu sonuçlara göre, öğrenciler uzaktan eğitim sırasında iletişimin etkili olmasıyla ilgilenmekten ziyade, kendilerini ders içinde arka plana atmayı arzu etmektedirler. Bu şekilde dersin öğretmen 
tarafından işlenmesi de onların düşüncesine göre daha kolay olacaktır. Tüm bu çekincelerin temelinde öğretmen merkezli eğitime alışık olmak ve kalabalık sınıfların uzaktan eğitimde normal kabul edilmesi yatıyor olabilir. Bununla beraber bağlantı kalitesi ve çalışır bir kameraya sahip olmamanın da öğrenciler üstünde bir stres yarattı̆̆ görülmektedir.

\section{Eğitimde ve Yabancı Dil Eğitiminde İletişim}

Eğitime düşen sorumluluk, bir ülkenin yalnızca gelişmesine katkı sağlamak değil aynı zamanda bilinçli, kendi kültürünü ve toplumunu tanıyan bireylerin yetişmesine de olanak sağlamaktır. Çalışkan ve Yeşil'e göre (2005: 200) toplum üzerinde böyle önemli bir etkiye sahip olan öğretmenler güçlerini bir iletişim süreci olan eğitimi planlayan, uygulayan ve değerlendiren kişiler olmalarından alırlar.

Eğitim sürecinde öğretmenin davranış biyolojisinin etkili olduğunu belirten Çalışkan ve Yeşil (2005: 201) vücut diliyle verilen mesajların önemini vurgulamışlardır. Örneğin, kendinden emin bir kişi mücadele gücünü ortaya koymak için omuzlarının genişliğini gösterir, hatta politikacıların kendinden emin olduklarını göstermek için sükûnetlerini bozmadıkları bilinir. Ancak bilerek ya da bilmeden kullanılan bu dil bazen yanlış anlaşılmalara ve çatışmalara dahi sebep olabilmektedir. Eğitimcilerin iletişim becerileri yüksek kişiler olması gerekliliğinin sebebi de aslında burada yatar. Çünkü bir öğretmenin bir konuyu öğretebilmesi, öğrencileri ile sağlıklı iletişim kurabilmesine bağlıdır. $\mathrm{Bu}$ noktada, iletişim süreçlerine hâkimiyet sağlamaları için çeşitli dersler almaları gerekmektedir. Berk’e (2014: 577) göre öğretmenlerin almış oldukları bu bilgiyi öğrencilerin kendi aralarında sağlıklı bir iletişim kurulabilmeleri için onlara aktarması da bu şekilde mümkün olabilmektedir. Çalışkan ve Yeşil'e göre (2005: 201-202) öğretmenler sınıf içinde ve dışında etkili iletişimde bulunabilmek için, hem kendi davranışlarının farkında olmalı hem de öğrencilerin davranışlarını kestirebilmelidirler.

Sınıf ortamında iletişim çok yönlü olarak gerçekleşir. Dolayısıyla öğretim süreci ile iletişim sürecinin öğeleri arasında bir benzerlikten bahsedilebilir (Kızıloluk 2001: 154). Öğretim sürecinde kaynak, yani mesajı ileten kişi öğretmendir. Öğretmen, eğitim ve öğretimde iletişim sürecini başlatan en önemli etkendir. Sahip olduğu bilgi ve birikimlerini öğrencilerine hem sözlü hem de sözsüz olarak aktaran kişidir. Aktarılan mesaj (bilgi, beceri, davranış vb.), öğretmen tarafindan uygun olarak belirlenen yöntemle, bu durumda kanal ile (ses tonu, beden dili, el kol hareketleri vb.) öğrenciye aktarılır (Bayraktar 2015: 266).

Sınıf içerisinde öğrenciler arasında kişisel farklılıklar göz önünde tutulduğunda, iletilen mesajın her öğrenci tarafindan aynı düzeyde algılanmayacağı, bazen daha yavaş bazen de farklı iletişim türleriyle algılanabileceği gerçeği, öğretmen tarafından göz ardı edilmemelidir (Berk, 2014: 577). Öğretmene düşen sorumluluk yalnızca bilgiyi aktarmak değil aynı zamanda etkili iletişim becerilerini geliştirmek ve çok yönlü iletişim türlerini de kullanmaktır. Öğretmenlerin etkili bir iletişimi gerçekleştirebilmesi için beden dili, baş 
hareketleri, yüz ifadeleri, jest ve mimikler ile sınıfı yönlendirebilme becerisine sahip olmaları gerekmektedir (Çalışkan ve Yeşil 2005: 201).

Yabancı dil öğretimi, sadece çeşitli dil becerilerinin öğrencilere kazandırılması ile dilbilgisi konularının aktarımıyla sınırlı tutulmamalıdır. Bu alanda öğrenenlerin aynı zamanda o dille iletişim kurması ve yabancı dil öğrenimine ve hedef dilin kültürüne karşı ön yargılardan uzak, olumlu bir tutum geliştirmesi amaçlanmaktadır (MEB 2007). Öğrencinin başka bir toplumda iletişim kurabilmesi için gerekli olan bilgiye ve bunları kullanabilmesi için gerekli becerilere sahip olması gerekmektedir. Bu bilgi ve becerilere ise iletişimsel yeti denilmektedir. Diğer bir ifadeyle, dilde bulunan göstergelerin farklı ortamlarda, uygun yerlerde ve zamanında anlamlı olarak kullanılmasıdır. Bu yeti belli bir durumda kime, neyi ve nasıl söyleneceğini de bilmek anlamına gelir (Aktaş 2005: 90). Yabancı dile karşı öğrenme arzusu artan ve böylelikle amacına ulaşacak olan öğrencinin derse katılma isteği ile motivasyonu da artacaktır. Çünkü okul ya da sınıf ortamında oluşacak olan doğru ve etkili bir iletişim süreci, öğrencilerin motivasyonlarını doğrudan etkilemektedir (Dă̆ 2014: 199). Bu doğrultuda etkili bir yabanc1 dil eğitiminde sesli iletişim kanallarının yeterli gelmeyeceği, dolayısıyla kameraların bu sürece dahil edilmelerinin gerekliliği ortaya çıkar.

\section{Sonuç}

Günümüz yapılandırmacı eğitim paradigması öğretmenlere sadece bilgiyi doğrudan aktarmayı değil etkili iletişim kurarak, öğrencilerine rehberlik edebilme görevini de vermiştir. Uzaktan eğitim kavramı birçok alanda incelenmiş ve farklı modeller üzerinden açılanmıştır. Bu modeller incelendiğinde, sağlıklı ve etkili bir iletişimin oluşması için birtakım şartların yerine getirilmesi gerektiği vurgulanmaktadır.

Mevcut çalışmadaki alanyazın doğrultusunda varılan sonuca göre, sesli iletişimin vaz geçilmez destekçisi beden dili, jestler ve mimikler gelmektedir. Birçok araştırmacı etkili iletişimin aslında ağızdan çıkan kelimelerden daha çok sözlü ve sözsüz iletişimin birleşmesiyle ve bu iki unsurun birlikte kullanılmasıyla gerçekleştiğini belirtmiştir. İletişim biçimlerinin birlikte varoluşları uzaktan eğitim için düşünülürse, iletişim sürecinin öğretmen ile öğrenci arasında gerçekleşen sesli alışverişten öte bir durum olması gerektiği görülür. Öğreticilerin ve öğrenenlerin çevrimiçi sınıfları yüz yüze eğitimden farklı görmemeleri ve iletişim kanallarını gerek kamera gerekse mikrofon düzeyinde açmaları, iletişimin kalitesini artırabilir.

Uzaktan eğitimde kaliteli bir öğrenme ortamı, hem öğrencilerin hem de öğreticilerin çoklu medya becerilerine ve yeterli bir uzaktan eğitim donanımına sahip olmalarıyla gerçekleşebilir. Yeterli bir donanım; çağın gerekliliklerine uygun bir bilgisayar, web kameras1, kulaklıklı mikrofon ve ergonomik bir masa ve sandalye gibi en temel uzaktan eğitim gereksinimleridir. Öğrencilerin ve öğreticilerin gerek bilgisayar donanımlarının gerekse internet alt yapılarının yeterli olması eş zamanlı çevrimiçi eğitim için oldukça önem taşımaktadır. Başka bir ifadeyle, teknolojik ve ekonomik özgürlügün eğitimde ne derece önemli ve iç içe olduğunu da göstermektedir. İyi bir donanıma ek olarak, 
katılımcıların ergonomik açıdan rahat etmeleri, bilgisayar karşısında sabit duran katılımcıların fiziksel ve psikolojik yükünün azaltılması açısından önem kazanır.

Etkili bir uzaktan eğitim, tüm katılımcıların bireysel olarak sorumluluklarının olduğu, yüz yüze eğitimdeymiş gibi hem fiziksel hem de psikolojik olarak hazır olmaları gerektiği, iletişimin sesli ve görüntülü biçimde yapıldığı bir süreçtir. Eş zamanlı uzaktan eğitime dahil olacak öğrencilerin ve öğreticilerin, kulaklıklı mikrofonlarının olması gerek konsantrasyonu artırması gerekse arka plandaki gürültüyü azaltması açısından önemli bir gerekliliktir. Böyle bir kültürün toplumda yerleşmesi zaman alacaktır ancak eğitimin ve iletişimin temel esasları dahilinde bunun bir zorunluluk olduğu görülmektedir. Eğitim ve iletişim bilimcilerin nitelikli eş zamanlı eğitim konusuna eğilmeleri önem arz etmektedir. Eğitim kurumlarının bu noktada eş zamanlı uzaktan eğitimin işleyişinin ve dikkat edilmesi gereken hususların aktarılmasında görev ve sorumlulukları bulunmaktadır.

$\mathrm{Bu}$ çalışmada alanyazın çerçevesinde, özellikle klasik iletişim modelleri temel alınarak uzaktan eğitimde görüntülü ve sesli iletişimin önemi hakkında birtakım çıkarsamalara gidilmiştir. Yapılacak yeni çalışmalarda veri temelli, ampirik çalışmalarla öğrenci ve öğreticilerin görüşlerinden yararlanılabilir.

\section{Kaynakça}

Aktaş, Tahsin (2005): Yabancı Dil Öğretiminde İletişimsel Yeti. Dil ve Dilbilimi Çalışmaları Dergisi. Say1 1 (1), 89-100.

Ammenwerth, Elske / Hackl, Werner (2016): Aktivierung von TeilnehmerInnen in einem onlinebasierten Lernsetting: Ergebnisse und Erkenntnisse bei der Umstellung von Präsenz-auf OnlineLernen. Jutta Pauschenwein; Julia Weinzödl (Ed.): E-Learning: Warum nicht? Graz: FH JOANNEUM Gesellschaft, 48-54.

Bay, Bülent / Karataş, Fatih / Üstün, Bilal (2021): Yabancı Dil Hazırlık Sınıfı Öğrencileri Perspektifinden Pandemi Sürecinde Uzaktan Eğitim: Fenomenolojik Bir Çalışma. Diyalog. Interkulturelle Zeitschrift für Germanistik. 9 (1), 184-203.

Bayraktar, Hatice Vatansever (2015): Eğitim Ortamında Öğretmen Öğrenci İletişimi. Akademik Sosyal Araştırmalar Dergisi. Sayı 3 (18), 262-285.

Berk, Fatih Mehmet (2014): Yabancı Dil Öğretim Yöntemlerinde Sözsüz İletişim ve Beden Dili. Selçuk Üniversitesi Sosyal Bilimler Meslek Yüksekokulu Dergisi. Sayı 12 (1-2), 575-587.

Castelli, Frank R. / Sarvary, Mark A. (2021): Why students do not turn on their video cameras during online classes and an equitable and inclusive plan to encourage them to do so. Ecology and Evolution. Vol. 11 (8), 3565-3576.

Çalışkan, Behlül (2009): Enformasyonun Metalaşması Üzerine. Marmara İletişim Dergisi. Vol. 15. 2346.

Çalışkan, Nihat / Rüştü Yeşil (2005): Eğitim Sürecinde Öğretmenin Beden Dili. Ahi Evran Üniversitesi Kırşehir Eğitim Fakültesi Dergisi. Sayı 6.1, 199-207.

Dağ, İsa (2014): Etkili İletişimin Eğitim Yönetiminde Rolü. Journal Of Qafqaz University. 2.2. 199-214.

Demir, Sezgin (2020): 4 Kulakla Dinleme. https://www.e-koc.org/9372-2/ (Erişim Tarihi: 20.10.2021).

Erdoğan, İrfan (2005): Iletişsimi Anlamak. 2. Baskı. Ankara: Pozitif Matbaacılık. 
Erdönmez, Işıl (2019): İletişimin Döngüsel Süreci Bağlamında Sözlü İletişim. Uluslararası Sanat Kültür ve İletişim Dergisi. 2.1, 81-98.

Erkuş, Ahmet / Günlü, Ebru (2009): İletişim Tarzının ve Sözsüz İletişim Düzeyinin Çalışanların İş Performansına Etkisi: Beş Yıldızlı Otel İşletmelerinde Bir Araştırma. Anatolia: Turizm Araştırmaları Dergisi. 20.1, 7-24.

Genç, Salih Zeki / Engin, Gizem / Yardım, Tuğçe (2020): Pandemi (Covid-19) Sürecindeki Uzaktan Eğitim Uygulamalarına İlişkin Lisansüstü Öğrenci Görüşleri. Atatürk Üniversitesi Kazım Karabekir Eğitim Fakültesi Dergisi. 41, 134-158.

Horzum, Mehmet Barış (2011): Transaksiyonel Uzaklık Algısı Ölçeğinin Geliştirilmesi ve Karma Öğrenme Öğrencilerinin Transaksiyonel Uzaklık Algılarının Çeşitli Değişkenler Açısından İncelenmesi. Kuram ve Uygulamada Eğitim Bilimleri. Sayı 11 (3), 1571-1587.

İplikçi, Handan Güler (2015): İletişimde Temel Modeller ve Kitle İletişim Modelleri. Sosyal ve Beşeri Bilimler Dergisi. Say1 7 (2), 15-25.

Kaysi, Feyzi / Aydemir, Emrah (2017): Uzaktan Eğitim Süreçlerindeki Etkileşim Boyutlarının Değerlendirilmesi. Sosyal Bilimler Dergisi. Say1 4 (11), 778-790.

Kızıloluk, Hakkı (2001): Sınıf Ortamında Öğretmen Öğrenci İletişiminin Yatay veya Dikey Olmasının Öğrenme Üzerindeki Etkileri, C.Ü. Sosyal Bilimler Dergisi. Sayı 25 (1), 151-159.

MEB (2020): Canlı Sinıf Yazılımlarına Illişkin Açıklama. http://www.meb.gov.tr/canli-sinif-yazilimlarinailiskin-aciklama/haber/20654/tr/ (Son Erişim Tarihi: 10.08.2021).

MEB Mevzuat Bankası (2007): Millî Eğitim Bakanlı̆ğ Orta Öğretim Kurumları Ödül ve Disiplin Yönetmeliği. http://mevzuat.meb.gov.tr/html/26408_0.html/(Son Erişim Tarihi: 10.08.2021).

Ocak Mehmet Akif (2021): Alanyazın Incelemesi. 2. Baskı. Ankara: Nobel

Röhner, Jessica / Astrid Schütz (2020): Klassische Kommunikationsmodelle. Kriz, Jürgen (Ed.): Psychologie der Kommunikation. Basiswissen Psychologie. Berlin: Springer, 27-51.

Sucu, İpek (2020): Yeni Dünya Düzeninde Dönüşümün İletişim ve Medyadaki İlk Adımları: Covid-19 Sonun Başlangıcında Yeni Bir Dijital Çağ. JOHASS. Sayı 3 (2). Ankara: Taş Kitapevi, 556-566.

Üstünsel, Gülcan (2011): Etkili Illetişim Becerileri ve Beden Dili. Namık Kemal Üniversitesi Fen Bilimleri Enstitüsü Yüksel Lisans Tezi. Tekirdağ.

Zıllığlu, Merih (2007): Illetişim Nedir? İstanbul: Cem Yayınevi. 